\title{
Oligosaccharide Analysis Using Anion Attachment in Negative Mode Electrospray Mass Spectrometry
}

\author{
Yanjie Jiang and Richard B. Cole \\ Department of Chemistry, University of New Orleans, New Orleans, Louisiana, USA
}

\begin{abstract}
Eleven different anionic species were able to form adducts with neutral oligosaccharides at low cone voltage in negative ion mode electrospray mass spectrometry. Among them, fluoride and acetate have the ability to significantly enhance the absolute abundance of $[\mathrm{M}-\mathrm{H}]^{-}$for neutral oliogosaccharides, which otherwise have low tendencies to deprotonate due to the lack of a highly acidic group. Evidence shows that the source of high abundances of $[\mathrm{M}-\mathrm{H}]^{-}$for neutral oligosaccharides arises from the decomposition of $\left[\mathrm{M}+\mathrm{F}^{-}\right.$and $[\mathrm{M}+\mathrm{Ac}]^{-}$with neutral losses of HF and HAc, respectively. The chloride adducts have the best stability among all the adduct species investigated, and chloride adducts consistently appeared in higher abundances relative to $[\mathrm{M}-\mathrm{H}]^{-}$. In tandem mass spectrometry (ES-MS/MS) experiments, upon collision induced dissociation (CID), $\mathrm{F}^{-}$and $\mathrm{Ac}^{-}$adducts gave purely analyte-related product ions, i.e., no detection of the attaching anion and no incorporation of these anions into decomposition products. $\mathrm{Cl}^{-}$adducts produced both $\mathrm{Cl}^{-}$and analyte-related product ions. For the above three anions, CID of adduct species may be used for structural determination of neutral oligosaccharides because, in each case, structurally-informative fragment ions were produced. In the presence of $\mathrm{F}^{-}$and $\mathrm{Ac}^{-}$, simultaneous detection of acidic and neutral oligosaccharides was achieved, because the problem of the presence of an acidic group that can impede the deprotonation of a neutral oligosaccharide was minimized. The ratio of $\mathrm{Cl}^{-}$:nonCl-containing product ions obtained in CID spectra of chloride adducts of disaccharides was used to differentiate anomeric configurations of disaccharides. Density functional theory (DFT) was employed to evaluate the optimized structures of chloride adducts of disaccharides, and it was found that chloride anions favor close contact with the hydrogen from the anomeric hydroxyl group. Multiple hydrogen bonding further stabilizes the chloride adduct. (J Am Soc Mass Spectrom 2005, 16, 60-70) (C) 2004 American Society for Mass Spectrometry
\end{abstract}

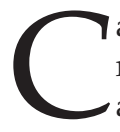
arbohydrates, also called saccharides, are the most abundant biological molecules and they are much more heterogeneous in structure than other biological molecules. It is well known that saccharides act as a major energy source (e.g., glucose and starch) and as a material that offers structural solidity (e.g., cellulose). Another interesting feature of saccharides is that they appear to play important roles in cell-surface recognition phenomena [1, 2]. An understanding of the saccharide structure is essential for understanding the varied functions of carbohydrates in biological systems.

Mass spectrometry has emerged as an important technique for oligosaccharide analysis [3-17]. Important innovations came through the introduction of electrospray (ES) and matrix-assisted laser desorption/ionization (MALDI). So far, oligosaccharide studies using mass spectrometry have focused mostly on the positive

Published online November 18, 2004

Address reprint requests to Dr. R. B. Cole, Department of Chemistry, University of New Orleans, 2000 Lakeshore Drive, New Orleans, Louisiana 70148, USA. E-mail: rcole@uno.edu mode via adduct formation with $\mathrm{H}^{+}$or with metal ions, among which the Group I [18-22], Group II [23] and first row transition metal [24-26] elements primarily have been used. It was found that lithium ions may ionize oligosaccharides more efficiently compared with other alkali metal ions [20], and that fragments derived from cross-ring cleavages may provide linkage information [18, 19]. In addition, the stereochemistry of glycosidic bonds has been studied using tandem mass spectrometry of diastereomeric cobalt-glucosyl-glucose disaccharide complexes [26].

Compared with the extensive number of studies conducted in positive mode mass spectrometry, fewer studies have been done to analyze oligosaccharides in the negative mode, with the exception of the sialylated oligosaccharides which contain at least one neuraminic acid moiety that readily deprotonates. Unlike sialylated oligosaccharides, because of the lack of an acidic group, neutral oligosaccharides exhibit a low tendency to form $[\mathrm{M}-\mathrm{H}]^{-}$.

It has been reported [27, 28] that the use of nanoscale electospray (flow rates of the order of tens of $\mathrm{nL} / \mathrm{min}$ ) can improve sensitivity for neutral oligo- 
saccharides relative to conventional microliter/min flow ES. Pfenninger et al. [29, 30] employed negative mode nanospray together with quadrupole ion trap mass spectrometry to analyze underivatized neutral oligosaccharides from human milk and found that their deprotonated molecules follow distinct fragmentation rules. Chai et al. [31] investigated the fragmentation of neutral underivatized oligosaccharides using negative mode ES-MS with collision induced dissociation (CID) on a Q-TOF instrument. Mulroney et al. [32] showed that ES-MS in the negative ion mode can be used to characterize glycosidic bond linkages in underivatized disaccharides. Wheeler and Harvey [16] investigated the negative mode ES-MS fragmentation spectra of 12 sialylated carbohydrates on a Q-TOF mass spectrometer. Often, sialylated oligosaccharides are detected with the best sensitivity as anions, while the asialylated species perform best in the positive ion mode [33].

Biological samples are usually comprised of neutral and acidic oligosaccharides. Most often, they are separated and analyzed independently from one another. Huang and Riggin [34] developed an HPLC/MS method that allows direct analysis of underivatized sialylated (containing acetyl neuraminic acid) and neutral oligosaccharides via online ES mass spectrometry in the positive mode.

The anion attachment approach described in the current paper represents a promising negative ion method for the simultaneous analysis of neutral and acidic oligosaccharides. There have been few studies on the analysis of oligosaccharides in the negative mode via the anion attachment approach. Henion and coworkers [27] observed low abundance acetate adducts alongside larger signals corresponding to multiply deprotonated polysialylated oligosaccharides. Wong et al. [35] reported the use of bisulfate as a dopant for oligosaccharides analysis in MALDI. Both bisulfate adducts, $\left[\mathrm{M}+\mathrm{HSO}_{4}\right]^{-}$, and bisulfate-containing derivatives, $\left[\mathrm{M}+\mathrm{HSO}_{4}-\mathrm{H}_{2} \mathrm{O}\right]^{-}$, were observed for neutral oligosaccharides with four or more sugar units. Zhu and Cole [36] investigated the use of chloride anions as additives in ES-MS for the ranking of gas-phase basicities and chloride affinities of monosaccharides, and it was also found that the decomposition of chloride adducts can give glycosidic bond linkage information for disaccharides. Cai et al. [37] found that chloride anions can form stable anionic adducts with neutral oligosaccharides in MALDI-TOF.

The current study is aimed at comparing the use of different anions for anion attachment and oligosaccharide analysis by ES-MS. The ability to distinguish $\alpha$ - and $\beta$-linked disaccharides via the anion attachment approach is also explored. Density functional theory calculations were employed to assist us in understanding the optimized anion-disaccharide adduct structures.

\section{Experimental}

\section{Chemicals}

Maltose, cellobiose, gentiobiose, isomaltose, laminaribiose, trehalose, and raffinose were obtained from Sigma Chemical Co. (St. Louis, MO). 3'-sialyllactose was obtained from Glyko (Novato, CA). Ammonium chloride, ammonium bromide, ammonium fluoride, ammonium bisulfate, ammonium acetate, ammonium trifuoroacetate, ammonium oxalate, ammonium tartrate, ammonium dihydrogen phosphate, sodium nitrate and citric acid were obtained from Aldrich (Milwaukee, WI). All materials were used as received without further purification. Saccharides and salts were prepared separately at $1.0 \times 10^{-3} \mathrm{M}$ in methanol/water $=9: 1$. The above solutions were mixed in a $1: 1$ ratio to make a final solution concentration of $5.0 \times 10^{-4} \mathrm{M}$ for both the disaccharides and salts.

\section{Instrumentation}

All mass spectrometry experiments were performed on a Quattro II triple quadrupole mass spectrometer (Micromass, Inc., Manchester, UK) equipped with an electrospray source. The ES capillary voltage was maintained at $-2.5 \mathrm{kV}$. Sample solutions were introduced into the ES source at a flow rate of $3.3 \mu \mathrm{L} / \mathrm{min}$ via a syringe pump. Nitrogen gas was used as both nebulizing gas and drying gas to improve ionization efficiency. Argon gas at a pressure of 2.3-2.5 $\times 10^{-4}$ mbar (gauge external to the hexapole collision cell) was used as the collision gas to acquire collision induced dissociation (CID) spectra. Collision energies (in the range of 5-40 $\mathrm{eV})$ are given in the laboratory frame of reference $\left(\mathrm{E}_{\mathrm{lab}}\right)$. In comparison studies of various disaccharides, because all employed disaccharides have the same molecular weights, constant $\mathrm{E}_{\text {lab }}$ values also mean uniform values in the center-of-mass frame of reference $\left(\mathrm{E}_{\mathrm{com}}\right)$. Mass spectra were acquired and processed using MassLynx software (version 3.0, Micromass).

\section{Density Functional Theory Calculations}

Individual disaccharide structures were generated using PC SPARTAN Plus version 2.0 (Wavefunction, Inc., Irvine, $C A$ ) and energy minimized using the MMFF94 force field to obtain low energy starting structures. To build the chloride adduct structures, the chloride ion was placed arbitrarily away from the disaccharide, and the preliminary structure was refined using a MMFF94 force field. The input structures were submitted to geometry optimization at the B3LYP / 6-31G* level in Gaussian 98, Revision A.3 [38] (Gaussian, Inc., Pittsburgh, PA). For all adduct calculations, the multiplicity was set to 1 and the charge state was set to -1 . 
Table 1. Adduct formation and decomposition of cellobiose with inorganic and organic anions ${ }^{\mathrm{a}}$

\begin{tabular}{|c|c|c|c|c|c|c|c|}
\hline Anion & Formula & $m / z$ & $\begin{array}{c}\text { Gas phase } \\
\text { basicity } \\
(\mathrm{kJ} / \mathrm{mol})^{f}\end{array}$ & {$[\mathrm{M}-\mathrm{H}]^{-\mathrm{d}}$} & {$[\mathrm{M}+\text { anion }]^{-\mathrm{d}}$} & $\begin{array}{l}\text { Upon } \\
\text { Anion }^{\mathrm{e}} \\
\end{array}$ & $\begin{array}{c}\text { CID }^{\mathrm{c}} \\
\text { Analyte } \\
\text { related }^{\mathrm{e}}\end{array}$ \\
\hline $\begin{array}{l}\text { Deprotonated } \\
\text { cellobiose }\end{array}$ & $\mathrm{C}_{12} \mathrm{H}_{21} \mathrm{O}_{11}^{-}$ & 341 & $\sim 1372$ & + & nd & nd & $*$ \\
\hline Fluoride & $\mathrm{F}^{-}$ & 19 & $1529 \pm 0.84$ & ++ & ++ & nd & $*$ \\
\hline Chloride & $\mathrm{Cl}^{-}$ & $35 / 37$ & $1372.8 \pm 0.84$ & + & +++ & $*$ & $*$ \\
\hline Bromide & $\mathrm{Br}^{-}$ & $79 / 81$ & $1331.8 \pm 0.84$ & + & +++ & * & nd \\
\hline Nitrate $^{(\mathrm{b})}$ & $\mathrm{NO}_{3}{ }^{-}$ & 62 & $1329.7 \pm 0.84$ & + & +++ & $*$ & nd \\
\hline Bisulfate & $\mathrm{HSO}_{4}{ }^{-}$ & 97 & $1265 \pm 10$ & ++ & +++ & * & nd \\
\hline $\begin{array}{l}\text { Dihydrogen } \\
\text { phosphate }\end{array}$ & $\mathrm{H}_{2} \mathrm{PO}_{4}^{-}$ & 97 & $1351 \pm 21$ & + & +++ & * & nd \\
\hline Acetate & $\mathrm{CH}_{3} \mathrm{COO}^{-}$ & 59 & $1427 \pm 8.4$ & ++ & ++ & nd & $*$ \\
\hline Trifluoro-acetate & $\mathrm{CF}_{3} \mathrm{COO}^{-}$ & 113 & $1328 \pm 8.4$ & + & +++ & $*$ & nd \\
\hline Oxalate & $\mathrm{HOOC}_{-} \mathrm{COO}^{-}$ & 89 & $\mathrm{~N} / \mathrm{A}$ & ++ & +++ & $*$ & nd \\
\hline Tartrate & $\mathrm{HOOC}-\mathrm{CH}(\mathrm{OH})-\mathrm{CH}(\mathrm{OH})-\mathrm{COO}^{-}$ & 149 & $N / A$ & ++ & ++ & * & nd \\
\hline Citrate & $\begin{array}{l}\mathrm{HOOC}-\mathrm{CH}_{2}-\mathrm{C}(\mathrm{OH})(\mathrm{COOH})- \\
\mathrm{CH}_{2}-\mathrm{COO}^{-}\end{array}$ & 191 & $\mathrm{~N} / \mathrm{A}$ & ++ & ++ & * & nd \\
\hline
\end{tabular}

${ }^{a}$ Ammonium salts are used as the anion source.

bodium salt is used as the anion source.

${ }^{\mathrm{c}} \mathrm{All} \mathrm{MS} / \mathrm{MS} \mathrm{CID}$ experiments were performed under the same conditions. Cone voltage was set at $15 \mathrm{~V}$, collision energy at 30 eV ( $\mathrm{E}_{\mathrm{LAB}}$ ), and the collision gas pressure at $2.4 \times 10^{-4}$ mbar.

${ }^{\mathrm{d}}$ Indicates intensity of [cellobiose $-\mathrm{H}^{-}$peak: + indicates absolute intensity $<10^{5},++$ indicates $10^{5}<$ absolute intensity $<10^{6},+++$ indicates $10^{6}$ $<$ absolute intensity $<10^{7}$.

e* Stands for appearance, nd for not detected.

ffFr the gas phase basicities of anions, see reference [41]

\section{Results and Discussion}

Most oligosaccharides are not charged in aqueous solutions near neutral $\mathrm{pH}$, unlike peptides and oligonucleotides, so the ionization efficiency is intrinsically low. In the positive mode, many reports have demonstrated that certain metal cations, especially Group I cations [18-22], can aid the ionization of oligosaccharides via formation of metal adducts. Moreover, the decomposition of such adducts may give richer information about the oligosaccharide structure than that of the protonated molecule. However, the number of reports detailing anion attachment approaches in the negative mode is far fewer than those published on cation attachment in the positive ion mode. In this work, the first investigation was focused on comparing different anions for neutral oligosaccharide analysis.

\section{Anion Selection}

Using cellobiose (Glc $\beta 1-4 \mathrm{Glc}$ ) as a model oligosaccharide, eleven anionic species, i.e., chloride, bromide, fluoride, bisulfate, acetate, trifuoroacetate, oxalate, tartrate, dihydrogen phosphate, nitrate, and citrate, were tested for their ability to form adducts with this disaccharide. Setting the cone voltage at $15 \mathrm{~V}$, all the tested anions could form observable adducts with cellobiose, and the obtained signal intensities are shown in Table 1. The ES-MS/MS studies investigating decompositions of [cellobiose + anion] ${ }^{-}$adducts (Figure 1 and Table 1) show that $\mathrm{F}^{-}$and $\mathrm{Ac}^{-}$adducts gave purely disaccharide-related product ions, whereas $\mathrm{Cl}^{-}$adducts produced both $\mathrm{Cl}^{-}$and disaccharide-related product ions. All the other tested anions gave only the respective anions as product ions (e.g., see bisulfate, Figure 1e), hence, they are not useful for detailed disaccharide structure determinations. For these reasons, the studies that follow focus on the behavior of $\mathrm{F}^{-}, \mathrm{Ac}^{-}$, and $\mathrm{Cl}^{-}$as anionic adducts of cellobiose.

\section{Anion Concentration Study}

The effect of anion concentration was evaluated next. Figure 2 shows the variations of absolute abundances of $[\mathrm{M}-\mathrm{H}]^{-}$in response to changing anion concentrations from $5 \times 10^{-5}$ to $5 \times 10^{-3} \mathrm{M}$ while holding cellobiose concentration constant at $5 \times 10^{-4} \mathrm{M}$ with the cone voltage fixed at $20 \mathrm{~V}$. The ratios of anion versus cellobiose concentration were 1:10, 3:10, 1:1, 10:3, and

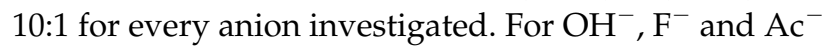
as attaching anions, the absolute abundance of [M $\mathrm{H}]^{-}$increased linearly with rising anion concentration up to $5 \times 10^{-4} \mathrm{M}$. Further augmentation of the anion concentration did not result in a clear increase in abundance of $[\mathrm{M}-\mathrm{H}]^{-}$for any of the anions tested; for $\mathrm{Cl}^{-}$, the absolute abundance of $[\mathrm{M}-\mathrm{H}]^{-}$barely changed over the entire range. Overall, this experiment indicated that an anion concentration of $5 \times 10^{-4} \mathrm{M}$ gave the optimal signal intensity for solutions containing cellobiose at this same concentration, so the anion versus disaccharide ratio was set at 1:1 for subsequent experiments. 


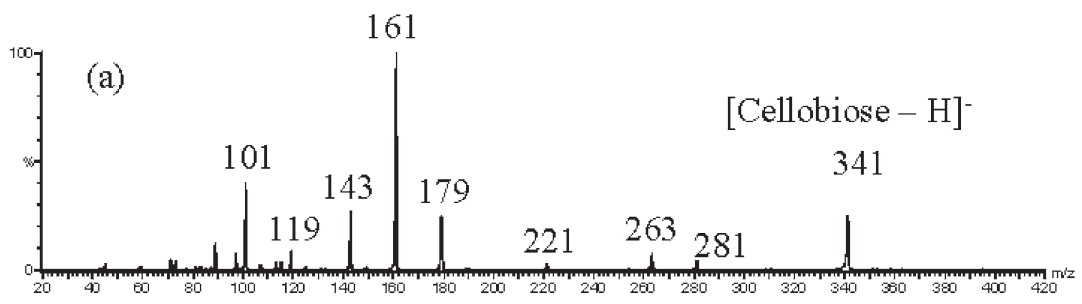

[Cellobiose $-\mathrm{H}^{-}$
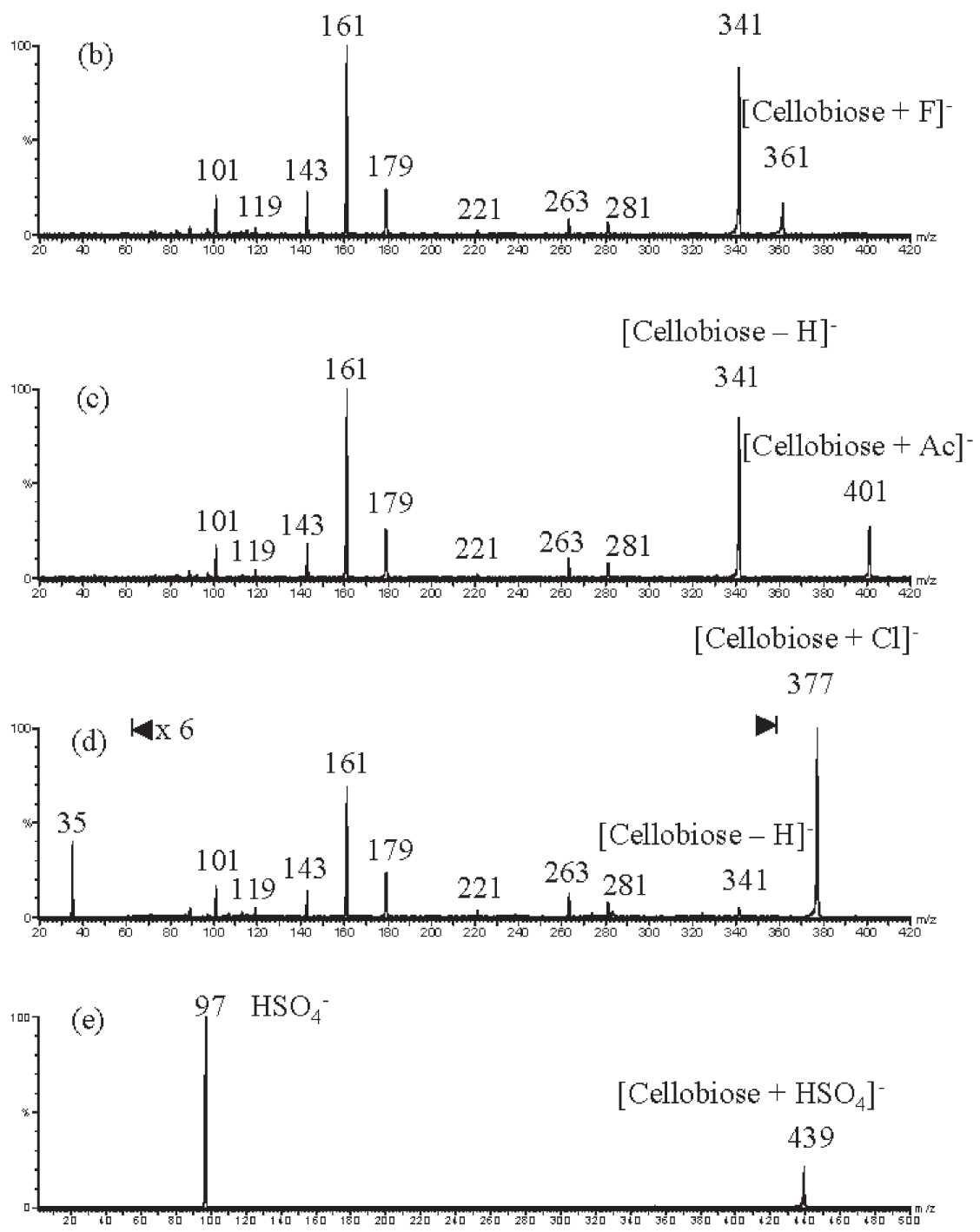

Figure 1. ES-MS/MS spectra of: (a) deprotonated cellobiose $[\mathrm{M}-\mathrm{H}]^{-}$; anionic adducts of cellobiose employing the following precursor ions: $(\mathbf{b})\left[\mathrm{M}+\mathrm{F}^{-}\right.$; (c) $[\mathrm{M}+\mathrm{Ac}]^{-}$; (d) $[\mathrm{M}+\mathrm{Cl}]^{-}$; and (e) $[\mathrm{M}+$ $\left.\mathrm{HSO}_{4}\right]^{-}$. Collision energy in the central hexapole was set at $30 \mathrm{eV}\left(\mathrm{E}_{\mathrm{LAB}}\right)$.

\section{Comparison of Anions and Influence of Cone Voltage}

When attaching anions are present, the cone voltage value exhibited a large impact on the appearance of mass spectra. Figure $3 a$ shows the absolute abundances of $[\mathrm{M}-\mathrm{H}]^{-}$as a function of cone voltage. Five different solutions were tested, i.e., pure cellobiose $\left(5 \times 10^{-4} \mathrm{M}\right)$, and cellobiose mixed with ammonium salts of $\mathrm{OH}^{-}$,
$\mathrm{CH}_{3} \mathrm{COO}^{-}, \mathrm{F}^{-}$, and $\mathrm{Cl}^{-}$(cellobiose and accompanying salt were each prepared at $5 \times 10^{-4} \mathrm{M}$ in all cases). For the pure cellobiose solution, the best sensitivity for $[\mathrm{M}-\mathrm{H}]^{-}$was obtained using cone voltages from 20 to $40 \mathrm{~V}$. At cone voltages below $20 \mathrm{~V}$, the transmission of all ions from the source to the quadrupole was low, while at cone voltages higher than $40 \mathrm{~V}$, decomposition of $[\mathrm{M}-\mathrm{H}]^{-}$became substantial. Addition of base to sample solutions is often practiced to aid the formation 


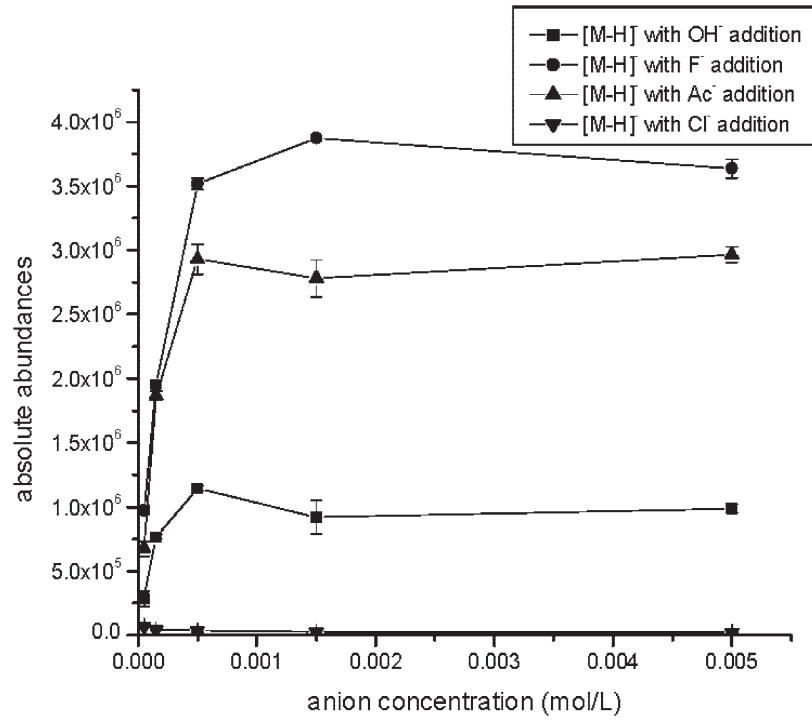

Figure 2. Absolute abundances of deprotonated cellobiose, [M $\mathrm{H}]^{-}$, versus anion concentration. Cellobiose was held at a constant final concentration of $5 \times 10^{-4} \mathrm{M}$, anion concentration was prepared at $5 \times 10^{-5}, 1.5 \times 10^{-4}, 5 \times 10^{-4}, 1.5 \times 10^{-3}$ or $5 \times 10^{-3}$ $\mathrm{M}$. The cone voltage was set at $20 \mathrm{~V}$. Each point was the average of three measurements and error bars represent the standard deviation.

of $[\mathrm{M}-\mathrm{H}]^{-}$for analytes which do not readily undergo deprotonation. In this study, the effect of base addition to the solution was tested. It was found that the abundance of $[\mathrm{M}-\mathrm{H}]^{-}$in the presence of $\mathrm{OH}^{-}$was increased approximately 10 - to 20 -fold relative to that of the pure cellobiose solution run under the same conditions. The influence of $\mathrm{F}^{-}$addition was different from that of base addition. In the presence of $\mathrm{F}^{-}$, using a cone voltage of $10 \mathrm{~V}$, the signal of $[\mathrm{M}-\mathrm{H}]^{-}$was about 10 times higher than that obtained from pure cellobiose solution. Most notably, with a cone voltage setting of 20 $\mathrm{V}$, the abundance of $[\mathrm{M}-\mathrm{H}]^{-}$was the highest achieved over all the experiments performed in this study, i.e., 100 times higher than found with the pure cellobiose solution under the same instrumental conditions. With further increases in the cone voltage, the abundance of $[\mathrm{M}-\mathrm{H}]^{-}$decreased due to the decomposition of [M $\mathrm{H}]^{-}$. It should be noted that the presence of $\mathrm{F}^{-}$gave a higher intensity peak for $[\mathrm{M}-\mathrm{H}]^{-}$than the addition of $\mathrm{OH}^{-}$. The general trend and tendencies observed during $\mathrm{Ac}^{-}$addition were similar to those observed for $\mathrm{F}^{-}$ addition except that the absolute abundance of [M $\mathrm{H}]^{-}$did not reach the same high values at cone voltages of 20 to $30 \mathrm{~V}$. In contrast, the presence of $\mathrm{Cl}^{-}$cannot increase the $[\mathrm{M}-\mathrm{H}]^{-}$signal intensity; instead, a high intensity $\left[\mathrm{M}+\mathrm{Cl}^{-}\right.$peak is observed (Figure $3 b$ ). It can thus be concluded that the presence of $\mathrm{OH}^{-}, \mathrm{F}^{-}$, or $\mathrm{Ac}^{-}$ can each increase the peak intensity of $[\mathrm{M}-\mathrm{H}]^{-}$, with $\mathrm{F}^{-}$addition offering the most dramatic increase, followed by $\mathrm{Ac}^{-}$, then $\mathrm{OH}^{-}$. Of course, increases in $[\mathrm{M}-$ $\mathrm{H}]^{-}$abundance will benefit MS/MS studies aimed at structural elucidation of oligosaccharides.
The ability of $\mathrm{F}^{-}$and $\mathrm{Ac}^{-}$to increase the abundance of $[\mathrm{M}-\mathrm{H}]^{-}$is proposed to result from the decomposition of the corresponding adducts involving loss of the conjugate acid of the respective anion. For the $\mathrm{F}^{-}$ example, Figure $3 \mathrm{~b}$ shows that, at a cone voltage of $10 \mathrm{~V}$, $\left[\mathrm{M}+\mathrm{F}^{-}\right.$was the predominant peak relative to [M $\mathrm{H}]^{-}$. After increasing the cone voltage to $20 \mathrm{~V}$, the peak intensity of $[\mathrm{M}+\mathrm{F}]^{-}$dropped off quickly while the peak intensity of $[\mathrm{M}-\mathrm{H}]^{-}$climbed dramatically. Combining the information derived from Figure $3 \mathrm{a}$ that, in the absence of $\mathrm{F}^{-}$, the intensity of $[\mathrm{M}-\mathrm{H}]^{-}$did not increase significantly upon changing the cone voltage from 10 to $20 \mathrm{~V}$, it can be inferred that in the presence of $\mathrm{F}^{-}$, the high abundance of $[\mathrm{M}-\mathrm{H}]^{-}$is attributable to the decomposition of $\left[\mathrm{M}+\mathrm{F}^{-}\right.$via $\mathrm{HF}$
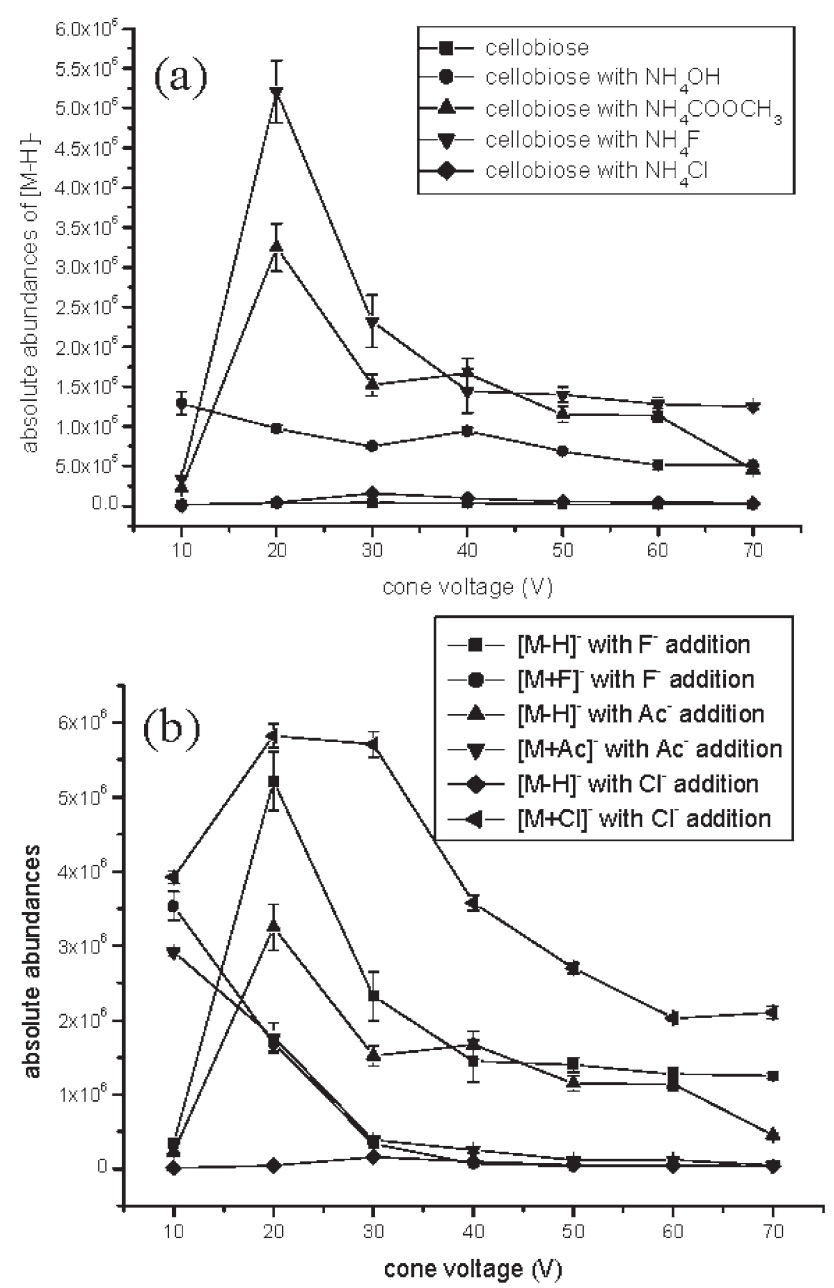

Figure 3. Ion abundance vs. cone voltage of deprotonated molecules and anionic adducts of cellobiose arising from five different solutions, i.e., pure cellobiose solution $\left(5 \times 10^{-4} \mathrm{M}\right)$, and cellobiose mixed with ammonium salts of $\mathrm{OH}^{-}, \mathrm{CH}_{3} \mathrm{COO}^{-}, \mathrm{F}^{-}$, and $\mathrm{Cl}^{-}$ (cellobiose and the salt were each prepared at $5 \times 10^{-4} \mathrm{M}$ in all cases). (a) Absolute abundances of deprotonated cellobiose [M $\mathrm{H}]^{-}$versus cone voltage; (b) absolute abundances of deprotonated cellobiose $[\mathrm{M}-\mathrm{H}]^{-}$and cellobiose adducts $[\mathrm{M}+\mathrm{A}]^{-}$with various anions $\left(\mathrm{A}^{-}=\right.$anion) versus cone voltage. Each point was the average of three measurements and error bars show the standard deviation. 
loss. This deduction is supported by CID studies that show a substantial peak corresponding to loss of neutral HF from $\left[\mathrm{M}+\mathrm{F}^{-}\right.$(Figure 1b). At a cone voltage of $20 \mathrm{~V}$ (Figure 3), the internal energy of $[\mathrm{M}+\mathrm{F}]^{-}$was high enough to cause the adduct to undergo substantial decomposition to form $[\mathrm{M}-\mathrm{H}]^{-}$, but low enough to prevent consecutive decomposition of $[\mathrm{M}-\mathrm{H}]^{-}$resulting in the highest abundance of $[\mathrm{M}-\mathrm{H}]^{-}$in the whole study. Under such optimized conditions, employing addition of $\mathrm{NH}_{4} \mathrm{~F}$ at $5 \times 10^{-5} \mathrm{M}$, cellobiose displayed a limit of detection $(\mathrm{S} / \mathrm{N}=3)$ of $1.3 \times 10^{-8} \mathrm{M}$ [flow rate of $1.7 \mu \mathrm{L} / \mathrm{min}$ for an average of $1 \mathrm{~min}$ acquisition time (22 fmol consumed )].

The stability of anionic adducts varied for the different attaching anions (Figure 3a). Chloride adducts appeared to be the most stable adduct species. Notably, under all the conditions tested, chloride adduct was always the predominant species compared to $[\mathrm{M}-\mathrm{H}]^{-}$ in agreement with previous studies $[39,40]$. The underlying reason for this phenomenon has been attributed to a close matching of the proton affinity of the deprotonated molecules $\left([\mathrm{M}-\mathrm{H}]^{-}\right)$with that of $\mathrm{Cl}^{-}$.

\section{CID of Anionic Adducts of Disaccharides for Linkage Differentiation}

ES-MS/MS product ion spectra of $\left[\mathrm{M}+\mathrm{F}^{-}\right.$and $[\mathrm{M}+$ $\mathrm{Ac}^{-}$of cellobiose gave purely disaccharide-related product ions, while $\left[\mathrm{M}+\mathrm{Cl}^{-}\right.$produced both $\mathrm{Cl}^{-}$and disaccharide-related product ions. The decomposition of fluoride adducts is a straight-forward process, with $\mathrm{F}^{-}$showing strong attraction for one proton leading to loss of $\mathrm{HF}$, thus leaving $[\mathrm{M}-\mathrm{H}]^{-}$and the possibility for consecutive decompositions. The decomposition of chloride adducts revealed a competition between $\mathrm{Cl}^{-}$ formation and disaccharide-related product ion formation. This contrast can be explained by considering that $\mathrm{F}^{-}$has a higher gas-phase basicity (Table 1) [41] than $[\mathrm{M}-\mathrm{H}]^{-}$of the disaccharide, so $\mathrm{F}^{-}$has a higher tendency to attract the proton of the disaccharide. On the other hand, $\mathrm{Cl}^{-}$has a gas-phase basicity similar to that of $[\mathrm{M}-\mathrm{H}]^{-}$of the disaccharide, so there is a more even competition to capture the proton during decomposition [36, 39].

As mentioned previously, $\mathrm{F}^{-}, \mathrm{Ac}^{-}$, and $\mathrm{Cl}^{-}$adducts may undergo decompositions to produce structurallyinformative fragment ions. Fragmentation of these three adducts leads to similar CID spectra (Figure $1 b-d$ ), with the appearance of the dissociated anion, $\mathrm{Cl}^{-}$(Figure $1 \mathrm{~d})$, and the variable abundance of deprotonated cellobiose $(m / z 341)$ as the main differences. Moreover, the fragmentation patterns were quite similar to that of $[\mathrm{M}-\mathrm{H}]^{-}$(Figure 1a) which indicates that the first step of the decomposition for each adduct was the loss of the conjugate acid of the anion prior to consecutive decomposition of $[\mathrm{M}-\mathrm{H}]^{-}$.

To widen the applicability of findings to other disaccharides, $\mathrm{F}^{-}$was employed to form adducts with a variety of glucopyranosyl-glucose disaccharides with different linkage positions, and the decomposition of each adduct was studied (Figure 4). The fragmentation patterns of $\left[\mathrm{M}+\mathrm{F}^{-}\right.$adducts were quite similar to the fragmentation patterns of $[\mathrm{M}-\mathrm{H}]^{-}$upon in-source decomposition reported by Mulroney et al. [32], which reinforces the notion that, in each case, the first step of decomposition of $\left[\mathrm{M}+\mathrm{F}^{-}\right.$is loss of HF. In addition, the CID product ion spectra of $[\mathrm{M}+\mathrm{F}]^{-}$adducts show great similarity with those of $[\mathrm{M}+\mathrm{Cl}]^{-}$except for the appearance of $\mathrm{Cl}^{-}$in the latter [36]. Thus, the decomposition of $[\mathrm{M}+\mathrm{F}]^{-}$can also be used for linkage position differentiation by inspection of the peaks characteristic of cross-ring cleavages appearing at $\mathrm{m} / \mathrm{z}$ values higher than $m / z 179$, and by the intensity ratio of $\mathrm{m} / \mathrm{z}$ 161 versus $m / z 179$ (glycosidic bond cleavages at either side of the oxygen). The high signal-to-noise ratios in CID spectra obtained using $[\mathrm{M}+\mathrm{F}]^{-}$as precursor ions was largely due to the high abundances of the precursor adducts as compared with $[\mathrm{M}-\mathrm{H}]^{-}$, and to the lack of competition during the first decomposition step (loss of $\mathrm{HF}) .\left[\mathrm{M}+\mathrm{Cl}^{-}\right.$ions appeared as the highest abundance precursor adducts, but decompositions yielded $\mathrm{Cl}^{-}$in competition with structurally-informative fragments.

\section{Anion Attachment for Simultaneous Analysis of Neutral and Acidic Oligosaccharides}

In the oligosaccharide pool from biological sources, it is often the case that neutral and acidic oligosaccharides coexist. Most reports treat the analyses of neutral and acidic oligosaccharides separately. Because $\mathrm{F}^{-}$and $\mathrm{Ac}^{-}$ addition can increase the abundance of $[\mathrm{M}-\mathrm{H}]^{-}$ions at cone voltages higher than $20 \mathrm{~V}$, these anions are good candidates for use in the simultaneous analysis of neutral and acidic oligosaccharides by negative mode mass spectrometry.

Raffinose (Gal $\alpha 1-6 \mathrm{Glc} \beta 1-2 \mathrm{Fru}$ ) was chosen as a model neutral oligosaccharide and $3^{\prime}$-sialyllactose (Neu5Ac $\alpha 2-3 \mathrm{Gal} \beta 1-4 \mathrm{Glc}$ ) as a model acidic oligosaccharide; the simultaneous detection of these compounds is demonstrated in Figure 5. As shown in a previous section, a cone voltage between 20 and $40 \mathrm{~V}$ allowed the detection of $[\mathrm{M}-\mathrm{H}]^{-}$for oligosaccharides, so for this study, the cone voltage was set at $40 \mathrm{~V}$. With the two oligosaccharides present in equal concentrations $(5 \times$ $\left.10^{-4} \mathrm{M}\right)$, Figure 5a shows that raffinose (mol. wt. $=503$ ) was barely detectable compared with $3^{\prime}$-sialyllactose $($ mol. wt. $=632)$ methanol:water (9:1). Figure 5b shows that the signal intensity of raffinose was enhanced to $1 / 5$ of the intensity of 3 -sialyllactose with the addition of base $\left(5 \times 10^{-4} \mathrm{M} \mathrm{NaOH}\right)$. Figure $5 \mathrm{c}$ and d show that the response of deprotonated raffinose was about $2 / 3$ that of $3^{\prime}$-sialyllactose upon addition of $\mathrm{F}^{-}$or $\mathrm{Ac}^{-}(5 \times$ $\left.10^{-4} \mathrm{M}\right) . \mathrm{F}^{-}$or $\mathrm{Ac}^{-}$addition was thus superior to $\mathrm{OH}^{-}$ in that the response was better, and the caustic nature of $\mathrm{OH}^{-}$addition may affect analyte stability in solution. 

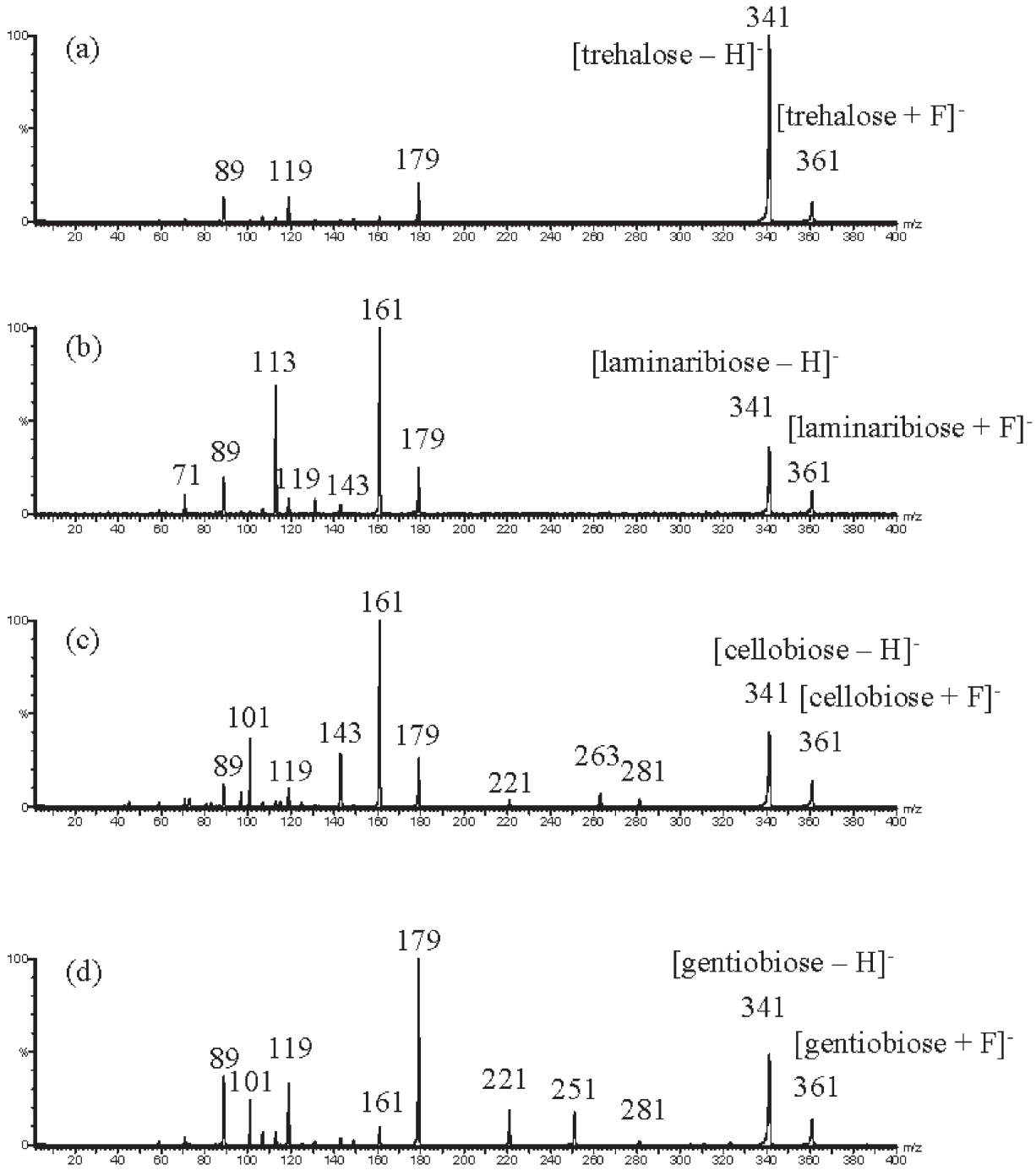

Figure 4. ES-MS/MS spectra of fluoride adducts of various glucopyranosyl-glucose disaccharides having different glycosidic bond linkages: (a) trehalose (Glc $\alpha 1-1 \mathrm{Glc})$; (b) laminaribiose (Glc $\beta 1-3 \mathrm{Glc}$ ); (c) cellobiose (Glc $\beta 1-4 \mathrm{Glc})$; and (d) gentiobiose (Glc $\beta 1-6 \mathrm{Glc})$. The collision energy was fixed at $30 \mathrm{eV}$ $\left(\mathrm{E}_{\mathrm{LAB}}\right)$.

\section{Chloride Adducts for Differentiating Anomeric Configuration of Disaccharides}

A study was undertaken to investigate whether ESMS/MS of chloride adducts could be used as a means to differentiate stereoisomeric disaccharides. Two pairs of disaccharides were obtained: gentiobiose (Glc $\beta 1-6 \mathrm{Glc})$ and isomaltose (Glc $\alpha 1-6 \mathrm{Glc})$, plus maltose (Glc $\alpha 1-4 \mathrm{Glc})$ and cellobiose (Glc $\beta 1-4 \mathrm{Glc})$. These isomeric pairs differ only in the anomeric configuration at the glycosidic bond, and the anomers constituting each pair are not readily distinguishable based solely upon relative abundances of oligosaccharide-related product ions in ESMS/MS spectra. Upon low-energy CID, there are two lowest energy possibilities for chloride adducts to undergo decompositions. One pathway is to simply form chloride (Pathway 1), while the other pathway is loss of $\mathrm{HCl}$ to leave $[\mathrm{M}-\mathrm{H}]^{-}$(Pathway 2) which may undergo consecutive decomposition. For each disaccharide pair, Figure $6 \mathrm{a}$ and $\mathrm{b}$ show that the ratio of $\mathrm{Cl}^{-} /$non- $\mathrm{Cl}$ product ions is heavily dependent on the CID conditions. In both figures, as the collision energy was increased, the ratio of $\mathrm{Cl}^{-} /$non- $\mathrm{Cl}$ product ions rose. At low collision energy $\left(\mathrm{E}_{\mathrm{lab}}\right)$, the ratio of $\mathrm{Cl}^{-} /$non- $\mathrm{Cl}$ product ions was below 1, which indicated that Pathway 1 was less favorable than Pathway 2. At high collision energy, the ratio of $\mathrm{Cl}^{-} /$non- $\mathrm{Cl}$ product ions was above 1, which indicated that Pathway 1 had become more favorable than Pathway 2. Considering the numerous available electropositive hydrogens (e.g., each hydroxyl hydrogen on the disaccharides), it is reasonable to assume that a distribution of structures of chloride adducts exists, with $\mathrm{Cl}^{-}$attached to various hydroxyl hydrogens, including conformations exhibiting multiple hydrogen bonding [40]. However, in order 

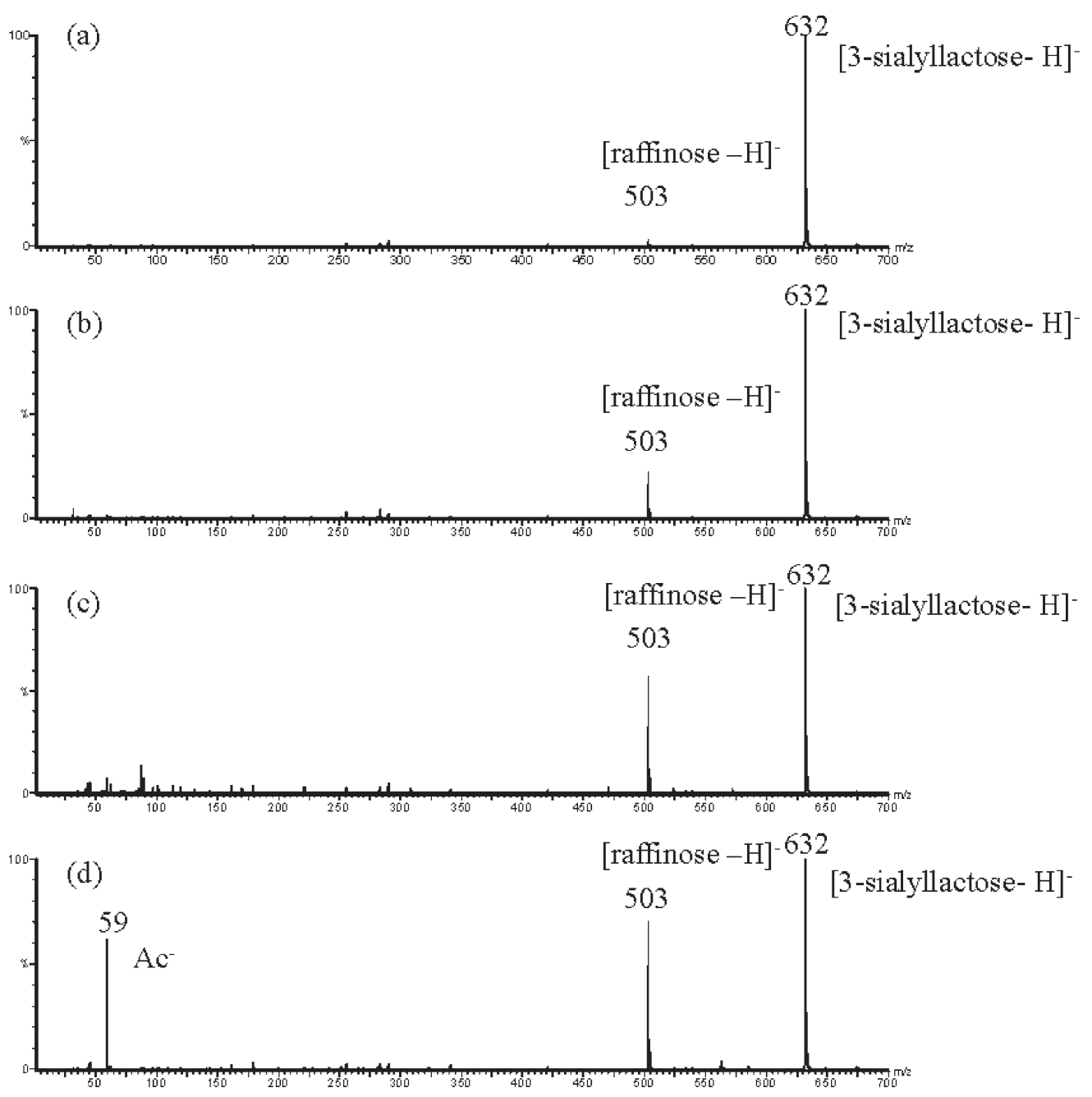

Figure 5. ES-MS spectra of a solution containing raffinose (Gal $\alpha 1-6 \mathrm{Glc} \alpha 1-2 \mathrm{Fru})$ and $3^{\prime}$-sialyllactose, each at $5 \times 10^{-4} \mathrm{M}$ : (a) in methanol:water (9:1); (b) with $5 \times 10^{-4} \mathrm{M} \mathrm{OH}^{-}$added; (c) with $5 \times 10^{-4}$ $\mathrm{M} \mathrm{F}^{-}$added as ammonium salt; and (d) with $5 \times 10^{-4} \mathrm{M} \mathrm{Ac}^{-}$added as ammonium salt.

to decompose via loss of neutral $\mathrm{HCl}$ in preference to departure of $\mathrm{Cl}^{-}$, chloride may be required to be located near to the most acidic proton (the hydroxyl hydrogen at the anomeric reducing end). At low collision energy, it is conceivable that energy was consumed in reorienting the $\mathrm{Cl}^{-}$closer to the most acidic hydrogen via movement along the potential energy surface of the ion-dipole complex. This mechanism can account for the tendency to lose neutral $\mathrm{HCl}$ at low collision energy. At high collision energy, however, it is rationalized that the excess energy present tended to favor $\mathrm{Cl}^{-}$departure before it could reach the most acidic proton, leading to a higher rate of $\mathrm{Cl}^{-}$loss vs. $\mathrm{HCl}$ loss at high collision energy.

For the 1-6 linkage disaccharides tested, the $\mathrm{Cl}^{-}$/ non- $\mathrm{Cl}$ ratio was higher for the $\alpha$ isomer (isomaltose) than for the corresponding $\beta$ isomer (gentiobiose) at every collision energy (Figure 6a). Conversely, for the 1-4 linkage disaccharides tested, the $\mathrm{Cl}^{-} /$non- $\mathrm{Cl}$ ratio was always higher for the $\beta$ isomer (cellobiose) than for the corresponding $\alpha$ isomer (maltose, Figure $6 \mathrm{~b}$ ). The differentiation of anomeric configurations is thus possible based upon the different tendency to form $\mathrm{Cl}^{-}$ versus $[\mathrm{M}-\mathrm{H}]^{-}$and consecutive decompositions.

\section{Density Functional Theory Calculations}

Computer modeling is a valuable approach to visualize the interaction between a neutral analyte and the attaching anion. Efforts have been made to study halide adducts of olefins [42], chloride adducts of acetylene [43], and halide adducts of $\alpha$-D-glucose [40]. The aim in the present study was to gain insight into the probable attaching position of chloride anion onto cellobiose and maltose disaccharides. Carbohydrates have both extensive hydrogen bonding possibilities and anomeric effects, so modeling results are sensitive to the level of calculation. B3LYP/6-31G* was chosen because it has been used previously to study the minimum energy conformation of monosaccharides [44-49], and it is a higher level calculation compared to the $\mathrm{HF} / 6-31 \mathrm{G}^{*}$ level. The HF/6-31G* level of theory was employed 


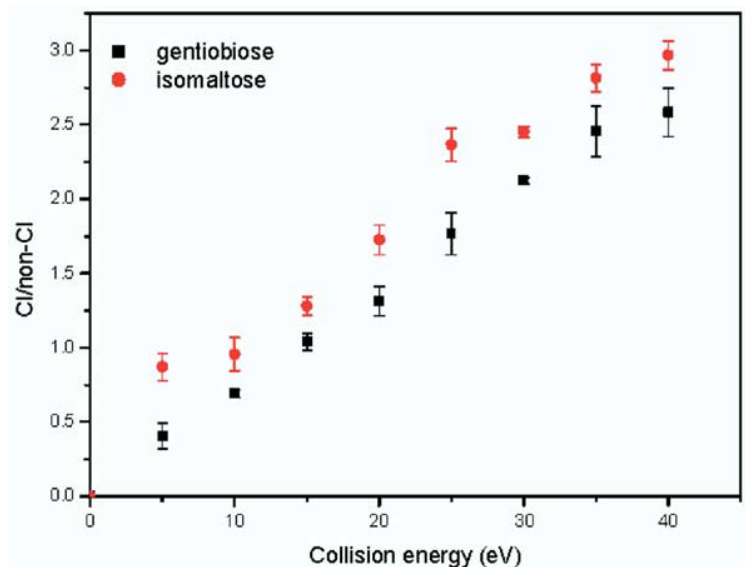

(a)

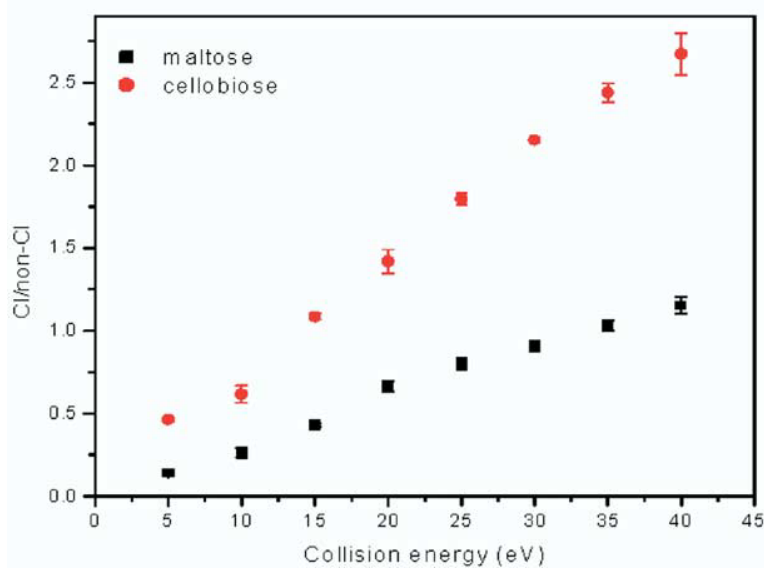

(b)

Figure 6. The relative ratio of $\mathrm{Cl}^{-} /$non- $\mathrm{Cl}$ product ions versus collision energy (laboratory frame of reference) for anomeric pairs: (a) gentiobiose (Glc $\beta 1-6 \mathrm{Glc}$ ) and isomaltose (Glc $\alpha 1-6 \mathrm{Glc}$ ); (b) maltose (Glc $\alpha 1-4 \mathrm{Glc})$ and cellobiose (Glc $\beta 1-4 \mathrm{Glc})$.

elsewhere to calculate relaxed potential energy surfaces for 12 analogs of disaccharides [50]. In the latter study, analogs were made by replacing glucose with tetrahydropyran; thus, hydrogen bonding effects were ignored. It was found that the torsional energy and the simple bulk of ring structures were major factors in determining favored disaccharide conformations.

In this study, the structures of chloride adducts with cellobiose and maltose were optimized at the B3LYP/ 6-31G* level using Gaussian 98, Revision A.3 [38]. The initial adduct structures were built using PC SPARTAN Plus version 2.0 on a template of cellobiose or maltose optimized by a MMFF94 conformer search. The chloride anion was placed away from the disaccharide and another MMFF94 conformer search was performed. The conformer search gave several geometries depending upon the initial placement of the anion. The adduct structures of different geometries were further optimized by B3LYP / 6-31G* calculations with the parameters set at the same criteria. Four pathways were checked for force and displacement convergence. Only certain input structures can give four-pathway convergence (maximum energy, RMS energy, maximum dis- placement, and RMS displacement), which marks a successful optimization procedure. Figure 7 shows the optimized structures for chloride adducts of cellobiose and maltose. Computer modeling suggests that $\mathrm{Cl}^{-}$ exhibits different favored binding positions for the two anomeric configurations. But, each time, the binding involved the hydrogen of the anomeric hydroxyl group in the reducing ring. This may be rationalized by considering that the electronegative chloride interacts with the most acidic hydrogen in the disaccharide molecule. Indirect evidence for this assertion was also given by the observation that the chloride adduct had a similar product ion spectrum as compared to $[\mathrm{M}-\mathrm{H}]^{-}$, hence the first step in chloride adduct decomposition was $[\mathrm{M}-\mathrm{H}]^{-}$formation via loss of $\mathrm{HCl}$; the least energy would be consumed in the latter loss when $\mathrm{Cl}^{-}$ was bound to the most acidic proton of the disaccharide. In addition, the optimized structures indicated that multiple hydrogen bonding was contributing to the high stability of the chloride adducts.

\section{Conclusions}

Fluoride and acetate anions were found to have the ability to significantly increase $[\mathrm{M}-\mathrm{H}]^{-}$formation for neutral oligosaccharides, even in the presence of acidic oligosaccharides which may severely suppress the formation of $[\mathrm{M}-\mathrm{H}]^{-}$from neutral oligosaccharides in ES mass spectrometry. Addition of these anions may find application in the analysis of oligosaccharide mixtures present in biological samples that contain both neutral

(a)

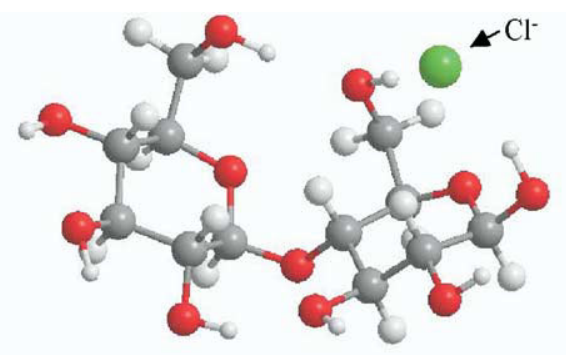

(b)

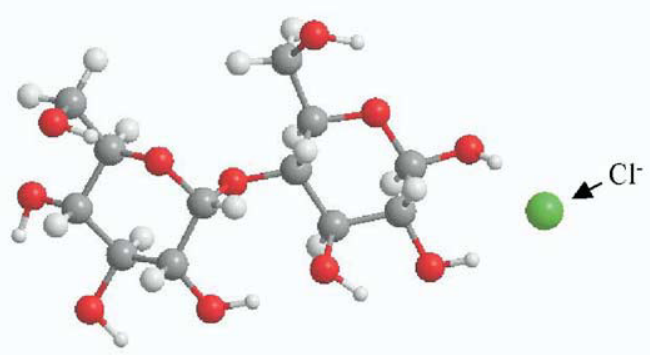

Figure 7. Computer modeling structure of the chloride adduct optimized at B3LYP / 6-31G* level using Gaussian 98, Revision A.3. (a) chloride adduct with cellobiose (Glc $\beta 1-4 \mathrm{Glc}$ ); (b) chloride adduct with (Glc $\alpha 1-4 \mathrm{Glc})$ maltose. In each case, the reducing end is on the right. 
and acidic oligosaccharides. Chloride adducts, however, gave even higher signals than $[\mathrm{M}-\mathrm{H}]^{-}$. The ES-MS/MS product ion spectra of fluoride, acetate, and chloride adducts with oligosaccharides showed great similarity with the ES-MS/MS spectrum of $[\mathrm{M}-\mathrm{H}]^{-}$of the same disaccharide, so the decomposition of these anionic adducts of disaccharides was shown to be initialized by loss of the conjugate acid of the anion to form $[\mathrm{M}-\mathrm{H}]^{-}$. The chloride adducts also tended to decompose by forming $\mathrm{Cl}^{-}$as product ions. The B3LYP/6-31G* level optimized chloride adduct structure showed that the proton involved in HA loss most probably comes from the anomeric hydroxyl group in the reducing ring. In addition, the abundance ratio of $\mathrm{Cl}^{-}$/non-Cl product ions from disaccharide adduct decompositions was shown to be useful for differentiating the anomeric configuration of glycosidic bond linkages.

\section{Acknowledgments}

Financial support for this research was provided by the National Science Foundation through grant no. CHE-9981948 and by the Louisiana Board of Regents through grant no. HEF(2001-06)-08.

\section{References}

1. Brockhausen, I.; Schutzbach, J.; Kuhns, W. Glycoproteins and Their Relationship to Human Disease. Acta Anatomica: 1998, 161, 36-78.

2. Varki, A. Biological Roles of Oligosaccharides: All of the Theories are Correct. Glycobiology 1993, 3, 97-130.

3. Cancilla, M. T.; Penn, S. G.; Lebrilla, C. B. Alkaline Degradation of Oligosaccharides Coupled with Matrix-Assisted Laser Desorption/Ionization Fourier Transform Mass Spectrometry: A Method for Sequencing Oligosaccharides. Anal. Chem. 1998, 70, 663-672.

4. Warren, M. E.; Kester, H.; Benen, J.; Colangelo, J.; Visser, J.; Bergmann C.; Orlando, R. Studies on the Glycosylation of Wild-Type and Mutant Forms of Aspergillus niger Pectin Methylesterase. Carbohydr. Res. 2002, 337, 803-812.

5. Xie, Y.; Tseng, K.; Lebrilla, C. B.; Hedrick, J. L. Targeted Use of Exoglycosidase Digestion for the Structural Elucidation of Neutral O-Linked Oligosaccharides. J. Am. Soc. Mass Spectom. 2001, 12, 877-884.

6. Harvey, D. J.; Wing, D. R.; Kuster, B.; Wilson, I. B. H. Composition of N-Linked Carbohydrates from Ovalbumin and Copurified Glycoproteins. J. Am. Soc. Mass Spectrom. 2000, 11, 564-571.

7. Weiskopt, A. S.; Vouros, P.; Harvey, D. J. Electrospray Ionization-Ion Trap Mass Spectrometry for Structural Analysis of Complex N-Linked Glycoprotein Oligosaccharides. Anal. Chem. 1998, 70, 4441-4447.

8. Papac, D. I.; Wang, A.; Jones, A. J. Analysis of Acidic Oligosaccharides and Glycopeptides by Matrix-Assisted Laser Desorption/Ionization Time-of-Flight Mass Spectrometry. Anal. Chem. 1996, 68, 3215-3223.

9. Yang, Y.; Orlando, R. Simplifying the Exoglycosidase Digestion/MALDI-MS Procedures for Sequencing N-Linked Carbohydrate Side Chains. Anal. Chem. 1996, 68, 570-572.

10. Huang, Y.; Mechref, Y.; Novotny, M. V. Microscale Nonreductive Release of O-Linked Gglycans for Subsequent Analysis Through MALDI Mass Spectrometry and Capillary Electrophoresis. Anal. Chem. 2001, 73, 6063-6069.
11. Tseng, K.; Hedrick, J. L.; Lebrilla, C. B. Catalog-Library Approach for the Rapid and Sensitive Structural Elucidation of Oligosaccharides. Anal. Chem. 1999, 71, 3745-3747.

12. Colangelo, J.; Licon, V.; Benen, J.; Visser, J.; Bergmann, C.; Orlando, R. Characterization of the Glycosylation of Recombinant Endopolygalacturonase I from Aspergillus niger. Rapid Commun. Mass Spectrom. 1999, 13, 2382-2387.

13. Leavell, M. D.; Leary, J. A. Stabilization and Linkage Analysis of Metal-Ligated Sialic Acid Containing Oligosaccharides. J. Am. Soc. Mass Spectrom. 2001, 12, 528-536.

14. Harvey, D. J. Ionization and Collision-Induced Fragmentation of N-Linked and Related Carbohydrates Using Divalent Cations. J. Am. Soc. Mass Spectrom. 2001, 12, 926-937.

15. Tseng, K.; Wang, H.; Lebrilla, C. B.; Bonnell, B.; Hedrick, J. Identification and Structural Elucidation of Lectin-Binding Oligosaccharides by Bioaffinity Matrix-Assisted Laser Desorption/Ionization Fourier Transform Mass Spectrometry. Anal. Chem. 2001, 73, 3556-3561.

16. Wheeler, S. F.; Harvey, D. J. Negative Ion Mass Spectrometry of Sialylated Carbohydrates: Discrimination of N-Acetylneuraminic Acid Linkages by MALDI-TOF and ESI-TOF Mass Spectrometry. Anal. Chem. 2000, 72, 5027-5039.

17. Colangelo, J.; Orlando, R. On-Target Exoglycosidase Digestions/MALDI-MS for Determining the Primary Structures of Carbohydrate Chains. Anal. Chem. 1999, 71, 1479-1482.

18. Hofmeister, G. E.; Zhou, Z.; Leary, J. A. Linkage Position Determination in Lithium-Cationized Disaccharides: Tandem Mass Spectrometry and Semiempirical Calculations. J. Am. Chem. Soc. 1991, 113, 5964-5970.

19. Zhou, Z.; Ogden, S.; Leary, J. A. Linkage Position Determination in Oligosaccharides: Mass Spectrometry (MS/MS) Study of Lithium-Cationized Carbohydrates. J. Org. Chem. 1990, 55, $5444-5446$.

20. Harvey, D. J. Collision-Induced Fragmentation of Underivatized N-linked Carbohydrates Ionized by Electrospray. J. Mass Spectrom. 2000, 35, 1178-1190.

21. Cancilla, M. T.; Penn, S. G.; Carroll, J. A.; Lebrilla, C. B. Coordination of Alkali Metals to Oligosaccharides Dictates Fragmentation Behavior in Matrix Assisted Laser Desorption Ionization/Fourier Transform Mass Spectrometry. J. Am. Chem. Soc. 1996, 118, 6736-6745.

22. Penn, S. G.; Cancilla, M. T.; Lebrilla, C. B. Collision-Induced Dissociation of Branched Oligosaccharide Ions with Analysis and Calculation of Relative Dissociation Thresholds. Anal. Chem. 1996, 68, 2331-2339.

23. Fura, A.; Leary, J. A. Differentiation of Calcium(2+)- and Magnesium(2+)-Coordinated Branched Trisaccharide Isomers: An Electrospray Ionization and Tandem Mass Spectrometry Study. Anal. Chem. 1993, 65, 2805-2808.

24. Ngoka, L. C.; Gal, J.-F.; Lebrilla, C. B. Effects of Cations and Charge Types on the Metastable Decay Rates of Oligosaccharides. Anal. Chem. 1994, 66, 692-698.

25. Sible, E.; Brimmer, S.; Leary, J. A. Interaction of First Row Transition Metals with $\alpha 1-3, \alpha 1-6$ Mannotriose and Conserved Trimannosyl Core Oligosaccharides: A Comparative Electrospray Ionization Study of Doubly and Singly Charged Complexes. J. Am. Soc. Mass Spectrom. 1997, 8, 32-42.

26. Smith, G.; Leary, J. A. Differentiation of Stereochemistry of Glycosidic Bond Configuration: Tandem Mass Spectrometry of Diastereomeric Cobalt-Glucosyl-Glucose Disaccharide Complexes. J. Am. Soc. Mass Spectrom. 1996, 7, 953-957.

27. Duffin, K. L.; Weply, J. K.; Huang, E.; Henion, D. J. Characterization of N-Linked Oligosaccharides by Electrospray and Tandem Mass Spectrometry. Anal. Chem. 1992, 64, 1440-1448.

28. Bahr, U.; Pfenninger, A.; Karas, M.; Stahl, B. High-Sensitivity Analysis of Neutral Underivatized Oligosaccharides by Nano- 
electrospray Mass Spectrometry. Anal. Chem. 1997, 69, $4530-4535$.

29. Pfenninger, A.; Karas, M.; Finke, B.; Stahl, B. Structural Analysis of Underivatized Neutral Human Milk Oligosaccharides in the Negative Ion Mode by Nano-Electrospray MSn. Part 1: Methodology. J. Am. Soc. Mass Spectrom. 2002, 13, 1331-1340.

30. Pfenninger, A.; Karas, M.; Finke, B.; Stahl, B. Structural Analysis of Underivatized Neutral Human Milk Oligosaccharides in the Negative Ion Mode by Nano-Electrospray MSn. Part 2: Application to Isomeric Mixtures. J. Am. Soc. Mass Spectrom. 2002, 13, 1341-1348.

31. Chai, W.; Piskarev, V.; Lawson, A. M. Negative-Ion Electrospray Mass Spectrometry of Neutral Underivatized Oligosaccharides. Anal. Chem. 2001, 73, 651-657.

32. Mulroney, B.; Traeger, J. C.; Stone, B. A. Determination of Both Linkage Position and Anomeric Configuration in Underivatized Glucopyranosyl Disaccharides by Electrospray Mass Spectrometry. J. Mass Spectrom. 1995, 30, 1277-1283.

33. Harvey, D. J. Matrix-Assisted Laser Desorption/Ionization Mass Spectrometry of Oligosaccharides and Glycoconjugates. J. Chromatogr. 1996, 720, 429-446.

34. Huang, L.; Riggin, R. M. Analysis of Nonderivatized Neutral and Sialylated Oligosaccharides by Electrospray Mass Spectrometry. Anal. Chem. 2000, 72, 3539-3546.

35. Wong, A. W.; Wang, H.; Lebrilla, C. B. Selection of Anionic Dopant for Quantifying Desialylation Reactions with MALDIFTMS. Anal. Chem. 2000, 72, 1419-1425.

36. Zhu, J.; Cole, R. B. Ranking of Gas-Phase Acidities and Chloride Affinities of Monosaccharides and Linkage Specificity in Collision-Induced Decompositions of Negative Ion Electrospray-Generated Chloride Adducts of Oligosaccharides. J. Am. Soc. Mass Spectrom. 2001, 12, 1193-1204.

37. Cai, Y.; Jiang, Y.; Cole, R. B. Anionic Adducts of Oligosaccharides by Matrix-Assisted Laser Desorption/Ionization Timeof-Flight Mass Spectrometry. Anal. Chem. 2003, 75, 1638-1644.

38. Frisch, M. J.; Trucks, G. W.; Schlegel, H. B.; Scuseria, G. E.; Robb, M. A.; Cheeseman, J. R.; Zakrzewski, V. G.; Montgomery, J. A., Jr.; Stratmann, R. E.; Burant, J. C.; Dapprich, S.; Millam, J. M.; Daniels, A. D.; Kudin, K. N.; Strain, M. C.; Farkas, O.; Tomasi, J.; Barone, V.; Cossi, M.; Cammi, R.; Mennucci, B.; Pomelli, C.; Adamo, C.; Clifford, S.; Ochterski, J.; Petersson, G. A.; Ayala, P. Y.; Cui, Q.; Morokuma, K.; Malik, D. K.; Rabuck, A. D.; Raghavachari, K.; Foresman, J. B.; Cioslowski, J.; Ortiz, J. V.; Stefanov, B. B.; Liu, G.; Liashenko, A.; Piskorz, P.; Komaromi, I.; Gomperts, R.; Martin, R. L.; Fox, D. J.; Keith, T.; Al-Laham, M. A.; Peng, C. Y.; Nanayakkara, A.;
Gonzalez, C.; Challacombe, M.; Gill, P. M. W.; Johnson, B.; Chen, W.; Wong, M. W.; Andres, J. L.; Head-Gordon, M.; Replogle, E. S.; Pople, J. A. Gaussian 98, Rev 3; Gaussian, Inc., Pittsburgh, PA, 1998.

39. Cai, Y.; Cole, R. B. Stabilization of Anionic Adducts in Negative Ion Electrospray Mass Spectrometry. Anal. Chem. 2002, 74, 985-991.

40. Cai, Y.; Concha, M. C.; Murray, J. S.; Cole, R. B. Evaluation of the Role of Multiple Hydrogen Bonding in Offering Stability to Negative Ion Adducts in Electrospray Mass Spectrometry. J. Am. Soc. Mass Spectrom. 2002, 13, 1360-1369.

41. Mallard, W. G.; Linstrom, P. J. National Institute of Standards and Technology: Gaithersburg MD, 20899 (http:// webbook.nist.gov), February 2000.

42. Hiraoka, K.; Katsuragawa, J.; Sugiyama, T.; Kojima, T.; Yamabe, S. Hydrogen Bonds in Gas-Phase Clusters Between Halide Ions and Olefins. J. Am. Soc. Mass Spectrom. 2001, 12, 144-149.

43. Meuwly, M.; Wolynec, P. P.; Bieske, E. J. Potential Energy Surface and Lower Bound States of HCCH-Cl-. J. Chem. Phys. 2002, 116, 4948-4954.

44. Barrows, S. E.; Dulles, F. J.; Cramer, C. J.; French, A. D.; Truhlar, D. G. Relative Stability of Alternative Chair Forms and Hydroxymethyl Conformations of $\beta$-D-Glucopyranose. Carbohydr. Res. 1995, 276, 219-251.

45. Barrows, S. E.; Storer, J. W.; Cramer, C. J.; Truhar, D. G.; French, A. D.; Truhlar, D. G. Factors Controlling Relative Stability of Anomers and Hydroxymethyl Conformers of Glucopyranose. J. Comput. Chem. 1998, 19, 1111-1129.

46. Csonka, G. I.; Elias, K.; Csizmadia, I. G. Relative Stability of $1 \mathrm{C} 4$ and 4C1 Chair Forms of $\beta$-D-Glucose: A Density Functional Study. Chem. Phys. Lett. 1996, 257, 49-60.

47. Csonka, G. I.; Elias, K.; Csizmadia, I. G. Ab Initio and Density Functional Study of the Conformational Space of 1C4 $\alpha$-LFucose. J. Comput. Chem. 1997, 18, 330-342.

48. Csonka, G. I.; Elias, K.; Kolossvary, I.; Sosa, C. P.; Csizmadia, I. G. Theoretical Study of Alternative Ring Forms of $\alpha$-LFucopyranose. J. Phys. Chem. A 1998, 102, 1219-1229.

49. Lii, J. H.; Ma, B.; Allinger, N. L. Importance of Selecting Proper Basis Set in Quantum Mechanical Studies of Potential Energy Surfaces of Carbohydrates. J. Comput. Chem. 1999, 20, 15931603.

50. French, A. D.; Kelterer, A.; Johnson, G. P.; Dowd, M. K.; Cramer, C. J. HF/6-31G* Energy Surfaces for Disaccharide Analogs. J. Comput. Chem. 2001, 22, 65-78. 